\title{
Production of Bioplastic from Waste Newspaper Pulp and Drained Rice Starch Water
}

\author{
Akshita Kapoor, Rachin Sharma* and Soumya Shrivastava \\ Department of Biotechnology, S. D College of Engineering \& Technology, Muzaffarnagar-251001, India
}

\begin{abstract}
Received: 10 November, 2017; Accepted: 13 December, 2017; Published: 18 December, 2017
*Corresponding author: Rachin Sharma, Department of Biotechnology, S. D College of Engineering \& Technology, Muzaffarnagar-251001, India, Tel: +919634668776; E-mail: rachinsharma6@gmail.com
\end{abstract}

\begin{abstract}
Today, the world is cluttered with petrochemical plastic. The petroleum based plastics are very common in our live however everyone knows that these types of plastics show their ugly sight to the environment. Bioplastic is the ideal replacement of petrochemical plastic. In this context, bioplastic production is favored by using newspaper pulp and drained rice starch water with the aim of declining the cost of production of bioplastic. Polyactic acid (PLA), the most important type of bioplastics in regards to the consumption of volume. Here, newspapers are utilized as raw material in preparation of PLA. Newspapers are used by extracting cellulose present in paper pulp and by converting that cellulose into glucose units. This glucose produce lactic acid that can finally leads to the production of Polyactic acid (PLA) by the process of polymerization. In case of drained rice starch water: starch is converted to glucose and after that further process is same as in newspaper production method.
\end{abstract}

\section{Introduction}

Plastics are used in almost every place such as, in packaging material, in bottles, cell phones, printers, chairs, tables etc. It is also utilized by developing industries ranging from pharmaceutical to automobiles. Plastics are important material as they are durable and cost proficient to everyone. Plastics have create a large environmental problem such as soil infertility, choking water bodies, disposable problems. Incineration can also be done but it causes harmful effects to both humans and environment. In fact, "Americans use up 25 billion plastic bottles each year". Plastic is being used in a very large amount. However, plastic is very slow in its degradation as it takes from hundreds to thousands of years and also it is responsible for the quality degradation of environment i.e. lands and oceans. People are using petrochemical based plastic because it is cheap and being produced in a large amount while researchers and government bodies are worried about the quality of environment i.e. pollution created by Plastic.

There is no solution to remove the plastic from environment after use beacause it is not biodegradable neither it can incinerate as it releases a high amount of harmful gases to the environment and still remains stay up. So, the solution to protect our environment is to stop using plastic. Plastic is banned in many european countries and aslo in some indian states but that's not enough, we have to stop the production and use of plastic. Bioplastic can absolutely replace the plastic used in daily basis. Bioplastic can replace generally all the plastic products available at this time. It is biobased and biodegradable polymer which contains all the properties of synthetic plastic. Bioplastic is biobased that means it is made up of natural biomass like corn starch, vegetable fats, cellulose, biopolymers, microbiota and oils. Bioplastic can be made from agricultural by-products and also from used plastic bottles and containers using microorganisms.

The only problem with bioplastic is its manufacturing cost. Bioplastic is expensive in comparison to traditional plastic so bioplastic is not been used extensively. Researchers are working on the decline in production cost of bioplastic. Nowadays, bioplastic is made up of corn starch, potato starch, banana starch which are used by humans and animals for their living. Here, we are using waste things such as newspaper waste and rice starch water (which is also a waste material as raw material) for bioplastic production instead of using starch extracted from eatable substances. Newspapers are dumped into ocean for disposal which comes from 500,00 trees which are being cut every week and $88 \%$ of them is never recycled.

The only problem with bioplastic is its manufacturing cost. Bioplastic is expensive in comparison to traditional plastic so bioplastic is not been used extensively. Researchers are working on the decline in production cost of bioplastic. Nowadays, bioplastic is made up of corn starch, potato starch, banana starch which are used by humans and animals for their living. Here, we are using waste things such as newspaper waste and rice starch water (which is also a waste material as raw material) for bioplastic production instead of using starch extracted from eatable substances. Newspapers are dumped into ocean for disposal which comes from 500,00 trees which are being cut every week and $88 \%$ of them is never recycled.

\section{Production of bioplastic}

Micro biota provides a source of bioplastics from renewable sources. These are polyesters that are broadly dispersed in nature and collect intracellular in microorganisms in the form of storage granules, with physico-chemical properties similar to petrochemical plastics. Production of bio-plastics from 
microalgae and lots of plant sources is been done these days. Algae produce a range of base resources that can be used for bio-plastics production. Most significant are carbohydrates and hydrocarbons. The algae Botryococcus Botryococcus braunii has the capability to produce and excrete these materials into the medium. Annual market data update, which tell us that aptitude will increase from around 1.6 million tons in 2013 to approximately 6.7 million tons in 2018 .

The way of Bioplastics creation also does not influence biodegradability at all. Procedures can be synthethical or biotechnological, and the most common are grounding of plastics on the basis of a natural polymer, which is mechanically or chemically treated ,chemical synthesis of a monomer-based polymer, obtained by biotechnological change of renewable resources the use of lactic acid from the fermentation of sugars for the production of polylactic acid, PLA Production of nearly all bioplastics consequences in reduced carbon dioxide emissions compared to conventional alternatives, there is concern that the construction of a global bioeconomy required to produce bioplastic in large quantity could contribute to an accelerated rate of deforestation and soil erosion, and could unfavorably affect water supplies.

\section{Uses of bioplastic}

Bioplastic is widely used in:

- Packaging

- Consumer goods

- Automotive and Transport

- Building and Construction

- Textiles

- Agriculture \& Horticulture

- Electrics \& Electronics

- Others

\section{Conclusion}

It's a high time now to improve environmental condition in today's era, we need to switch on to other alternatives which should be suitable, harmless, useful and economical. So for glorious and sustainable future the demand for bioplastic should be increased and so its production. Cost of plastic out of fossil fuels is increasing day by day and we biotechnologist are finding ways to cut the cost of bioplastic. So, in coming days the cost would be balanced and it is also possible that bioplastic would cost less in comparison to plastics.

\section{References}

1. R E Drumright, P R Gruber and D E Henton, Polylactic Acid Technology. Adv Mater. 2000;12(23):1841-1843.

2. J S Dugan, Novel Properties of PLA fi bers, Research Fiber Innovation technology, Inc, INTC 2000, Texas, USA,2000.

3. D. J. Sawyer. Nonwovens World,10(2),49 (2001). W. Hoogsteen, A. R. Postema, A. J. Pennings, G. T. Brinke, and P. Zugen. Macromolecules, 23, 634 (1990). Fibre properties of PLA and PET Fibre properties PLA PET Specific gravity 1.25 1.39 Tm (o C) 130-175 254-260 Tenacity (g/d) 6.06 .0 Elastic recovery (5\% strain) 9365 Moisture regain (\%) $0.4-0.60 .2-0$.

4. Flammability Continues to burn for 2 mins after flame removed Continues to burn for 6 mins after flame removed Smoke generation $63 \mathrm{~m} 2 / \mathrm{kg} 394 \mathrm{~m} 2 / \mathrm{kg}$ Limiting oxygen index (\%) 26 20-22 Refractive index 1.35-1.45 1.54 398

5. H Tsuji, Y Ikada, William Bonfiel, Raymond Smith. Porous biodegradable polyesters. I. Preparation of porous poly(L-lactide) films by extraction of poly(ethylene oxide) from their blends]. Appl. Polym. Sci. 2000;75(5). Doi: 10.1002/(SICI)1097-4628(20000131)75.

6. Liviu-Iulian Palade, Hans J Lehermeier, andJohn R. Dorgan. Melt Rheology of High l-Content Poly(lactic acid). Macromolecules. 2001;34(5):1384-1390 .

7. S. Jacobsen, P Degée and H.G. Fritz. Polylactide (PLA) - a new way of production Polym. Eng Sci. 1999;39(7). Doi: 10.1002/pen.11518

8.H R Kricheldorf.Syntheses and application of polylactides. Chemosphere. 2001; 43(1):49-54.

9. E S Lipinsky and R G Sinclair. Comparative Analysis of the Effects of Time of Heat Setting and Wet Processing on Tensile Properties of Treated and Untreated Knitted PLA Fabric. Chem Eng Prog. 1986;82(8):26-32.

10. M Vert, G Schwacch, and J Coudane, J Macromol. Sci Pure. A32, 787 (1995).

11. J Lunt, Int Fiber J,15(3),48 (2000).

12.B Linnemann, M S Harwoko, T Gries. FIBER TABLE-Fiber Table polylactide fibers (PLA). Chemical Fibers International. 2003;53:426433.

13. M. Dartee, J. Lunt, and A. Shafer, Man-Made Fiber Year Book, August,29 (2001).

14.R S Blackburn, "Biodegradable and sustainable fi bres," I Edition. Woodhead Publishing Limited. 2005.

15.P. Gruber and M. O' Brien, Polylactides "NatureWorksTM PLA," Biopolymers, Polyester III: Applications and Commercial Products, 2002.

16.C. Lui, JCNN News Summaries - Japan Corporate News Network, Apr $5,2006$.

17.K. Yoshikazu, Lactron - a biodegradable fiber, its development and applications. 1999.

18.M. Kenjiro, High Polym, Japan, 52(No.11),840 (2003). 